\title{
軽量パネルの総合性能について
}

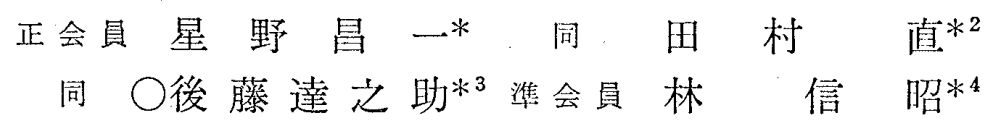

昭和 36〜37 年度にわたって研究してきた軽量パネル の試験結果を検討して，これを改良したパネルを試作 し，その性能を試験し部位別性能級別基準案によって壁 として使用した場合の号級を求めた。

\section{(1) パネルの設計方針}

a. パネル厚……特に曲げ剬性を高めるために必要な 構成材の厚さ (スパン比) は最少限木骨 $1 / 30$, 鉄骨 $1 / 40$, フォーム材などの心材では 1/50 1/60 程度がよいと考 えられ，したがって各補強形に态じた標準厚 $(\mathrm{mm})$ は つぎの通りとなる（面材の拹力が得られないような構成 の場合は補強材の愿さをこの值とする)。

\begin{tabular}{cc|c|c}
\hline 補強形式 & 外壁(スパン $2.5 \mathrm{~m}$ ) & 屋根 (スパン $3 \mathrm{~m})$ \\
\hline 木 & 骨 & 80 & 100 \\
鉄 & 骨 & 60 & 75 \\
心 & 材 & $40 \sim 50$ & $50 \sim 60$ \\
\hline
\end{tabular}

b. 外面材について……外装用に重点をおき，外面は 不燃材を用い防火性能は 10 分以上とし，一部のものは 屋外 2 級（屋内換算 20 30 分）とした。内面について

表一1 軽量パネルの総合性能表 (S 38 年度)

\begin{tabular}{|c|c|c|c|c|c|c|c|c|c|c|c|c|c|c|c|c|c|}
\hline 就 & & 满 & & 成 & & & & \pm & 那惊 & 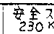 & $\begin{array}{lll}3 \\
\mathrm{~kg} / \mathrm{m}^{2}\end{array}$ & 行恵 & 17 & 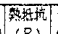 & 遮再 & $\pi$ & 均 \\
\hline g & 外面 材 & 材 & 内面材 & 補羍 材 & $\begin{array}{l}m \\
m / m\end{array}$ & $\left(\frac{2}{m} / \mathrm{m}^{2}\right.$ & 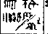 & 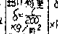 & 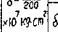 & $8 \times \frac{1}{100}$ & $\delta=\frac{1}{200}$ &  & $\min$ & 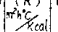 & $d B$ & 告数 & 8 simeng \\
\hline 1 &  & $\begin{array}{c}24 y=7 x-4 \\
(P=0.031 \\
20\end{array}$ & 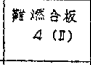 &  & 113 & \begin{tabular}{|}
34.4 \\
$(8-4)$
\end{tabular} & 3.2 & $\left|\begin{array}{l}689 \\
\langle A-i\rangle\end{array}\right|$ & 6 & 280 & 222 & $\left.\mid \begin{array}{c}0 \\
0 \times 25 \\
(4-6)\end{array}\right]$ & $5\left|\begin{array}{c}34^{\prime} \\
(c-3)\end{array}\right|$ & $\left|\begin{array}{cc}1.1 & 1 \\
(3.6)\end{array}\right|$ & $\left.\mid \begin{array}{r}30 \\
6-3\end{array}\right]$ & 4.2 & 1.3 \\
\hline 2 &  & 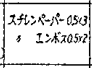 & ${ }_{9}$ & 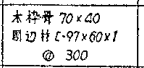 & 93 & $\left|\begin{array}{c}28.1 \\
(A-5)\end{array}\right|$ & 2.7 & $(404)$ & 3.6 & 235 & 185 & $\left|\begin{array}{c}10 \times 2.5 \\
(x-6)\end{array}\right|$ & $\mid \begin{array}{c}15 \\
(0.2)\end{array}$ & $(0.84)$ & $\left.\mid \begin{array}{l}(30) \\
(x-3)\end{array}\right]$ & 4.2 & 1.56 \\
\hline 3 & $\begin{array}{c}\text { て丰三大源 } 4 \\
\text { h } 47\end{array}$ & $\mid \begin{array}{c}p(y>77-4 \\
(\beta+0.04) \\
23-68\end{array}$ & 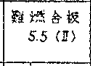 & 本椊 $23 \times 25$ & 59 & $\left|\begin{array}{r}84.5 \\
(A-63)\end{array}\right|$ & 3.4 & $\left|\begin{array}{c}153 \\
(c-3)\end{array}\right|$ & 1.35 & 168 & 133 & $\left|\begin{array}{c}20 \times 2 \\
(A-6)\end{array}\right| C$ & {$\left[\begin{array}{c}17 \\
(0-1)\end{array}\right.$} & $\mid \begin{array}{l}(1.1) \\
(B-4)\end{array}$ & $\left(\begin{array}{l}(26) \\
(0.23)\end{array}\right.$ & 3.7 & 1.1 \\
\hline 4 & 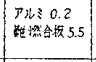 & {$\left[\begin{array}{c}x \neq b: 3 x-4 \\
20\end{array}\right.$} & {$\left[\begin{array}{c}5-3 \\
9\end{array}\right.$} & 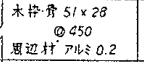 & 69 & {$\left[\begin{array}{c}15.9 \\
(4-6)\end{array}\right]$} & 2.3 & $\left|\begin{array}{c}119 \\
(C-3)\end{array}\right|$ & 1.2 & 162 & 128 & $\left|\begin{array}{l}10 \times 2.5 \\
\angle A-5,\end{array}\right|$ & $\left|\begin{array}{c}8 \\
(E-1)\end{array}\right|$ & $|(1.16)|$ & $\mid \begin{array}{l}(26) \\
(0-2)\end{array}$ & 3.5 & 1.5 \\
\hline 5 & 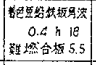 & $\begin{array}{c}x+b>7 x-4 \\
20\end{array}$ &  & 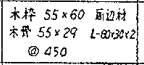 & 75 & $\left|\begin{array}{c}25.7 \\
(A-6)\end{array}\right|$ & 3.8 & $\left|\begin{array}{c}272 \\
\langle\beta-43\end{array}\right|$ & 2.4 & 205 & 163 & $\left.\mid \begin{array}{c}z 0 \times ? .5 \\
(A-6)\end{array}\right]$ & $\begin{array}{c}7 \\
(E-1)\end{array}$ & $\left(\begin{array}{c}1 \\
(8-6)\end{array} \mid\right.$ & $\begin{array}{l}(30) \\
(C-3)\end{array}$ & 3.8 & 1 \\
\hline 6 &  &  & 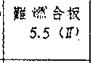 & 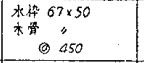 & 81 & $\left|\begin{array}{c}17.6 \\
(A-6)\end{array}\right|$ & 2.6 & $\left|\begin{array}{c}276 \\
(3-4)\end{array}\right|$ & 2.4 & 205 & 63 & $\left|\begin{array}{c}20 \times 2 \\
(A-6)\end{array}\right| C$ & $\left|\begin{array}{c}17^{\prime} \\
(0-25)\end{array}\right|$ & $\left|\begin{array}{c}0.001 \\
(3.4)\end{array}\right|$ & $\left|\begin{array}{l}(28) \\
(C-3)\end{array}\right|$ & 4 & 1.56 \\
\hline 7 & 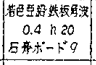 & $\begin{array}{c}210+7 t-4 \\
60\end{array}$ & $\begin{array}{c}0 \\
6\end{array}$ &  & 83. & $\left|\begin{array}{c}31 \\
(3-6)\end{array}\right|$ & 0.5 & $\left|\begin{array}{c}917 \\
(8.5)\end{array}\right|$ & 3.7 & 237 & 180 & $\left|\begin{array}{c}10 \times 2.5 \\
(A-6)\end{array}\right| C$ & {$\left[\begin{array}{c}18^{\prime} \\
(0.2)\end{array}\right.$} & $\left|\begin{array}{c}1.29 \\
(A-5)\end{array}\right|$ & $\left|\begin{array}{c}(3 t) \\
(c-3)\end{array}\right|$ & 4.2 & 0.93 \\
\hline 8 & 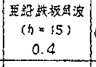 & 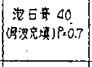 &  & 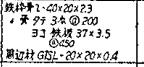 & 59 & {$\left[\begin{array}{c}49.7 \\
(8 \cdot 4)\end{array}\right]$} & 3.3 & $\left|\begin{array}{c}353 \\
69-4\end{array}\right|$ & 7.1 & 223 & 177 & {$\left[\begin{array}{c}20 \times 2 \\
(A-6)\end{array}\right][$} & $\left|\begin{array}{c}46^{\circ} \\
(c-3)\end{array}\right|$ & $\left|\begin{array}{l}\langle 0.551 \\
(c-3)\end{array}\right|$ & $\left|\begin{array}{r}35) \\
(c-3)\end{array}\right|$ & 3.8 & 1.15 \\
\hline 9 & 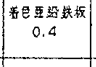 & 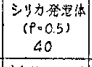 & 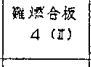 &  & 48 & {$\left[\begin{array}{r}9.9 \\
(4-5)\end{array} \mid\right.$} & 3.6 & $\begin{array}{c}145 \\
6-3:\end{array} \mid$ & 1.3 & $|167|$ & 132 & $\left|\begin{array}{l}20 \times 1.5 \\
(A-6)\end{array}\right|$ & $\begin{array}{c}27^{\circ} \\
0-23\end{array}$ & $(0.45)$ & $\begin{array}{l}(28) \\
(C-3)\end{array}$ & 3.5 & 0.87 \\
\hline 10 & 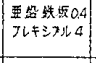 & $\mid \begin{array}{c}7+297 x-4 \\
(p=0.03) \\
22\end{array}$ & 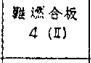 &  & 59 & $\left|\begin{array}{c}23.4 \\
6 A-55\end{array}\right|$ & 3.5 & $\mid \begin{array}{c}332 \\
(B-4)\end{array}$ & 2.9 & $21 \varepsilon$ & 173 & $\left|\begin{array}{c}20 \times 2.5 \\
2 A-6)\end{array}\right|:$ & $\mid \begin{array}{c}33^{\prime} \\
(c-3)\end{array}$ & $\left.\mid \begin{array}{c}(1.15) \\
(8-4)\end{array}\right]$ & $\left|\begin{array}{c}(20) \\
(C-3)\end{array}\right|$ & 4.2 & 1.2 \\
\hline 11 & $\begin{array}{c}\text { 石的开板 } \\
6\end{array}$ & 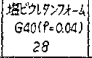 & $\begin{array}{c}74 \neq \equiv>A \\
4\end{array}$ & 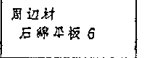 & 38 & $\left|\begin{array}{c}21.8 \\
(A-5)\end{array}\right|$ & 3.4 & $\left|\begin{array}{|l}187 \\
(C-3)\end{array}\right|$ & 1.65 & 180 & 143 & $\left.\mid \begin{array}{c}10 \times 1 \\
(A-5)\end{array}\right]$ & $\left|\begin{array}{c}1060 \\
00-13\end{array}\right|$ & $\mid(1,1)\}$ & $\left|\begin{array}{l}(29) \\
(c-3)\end{array}\right|$ & 3.5 & 1.03 \\
\hline 12 & 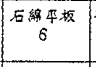 &  & 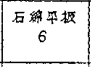 & 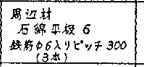 & 99 & $\left|\begin{array}{c}47.8 \\
(B-4)\end{array}\right|$ & 2.2 & {$\left[\begin{array}{c}157 \\
(c \cdot 3)\end{array}\right]$} & 1.6 & $\left(\begin{array}{l}1.00 \\
(212)\end{array}\right.$ & $\left\{\begin{array}{c}135 \\
167)\end{array}\right.$ & $\left|\begin{array}{rl}10 \times 25 \\
(A-6)\end{array}\right|$ & $\left|\begin{array}{c}30^{\circ} \\
(c-3)\end{array}\right|$ & $\left|\begin{array}{c}(0.093 \\
00-2)\end{array}\right|$ & $\left|\begin{array}{l}\{35) \\
(c-3)\end{array}\right|$ & 3.5 & 1.6 \\
\hline 13 & $\begin{array}{c}7 \downarrow \neq \vdots \rightarrow \cdots \\
3\end{array}$ &  & 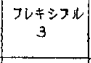 & 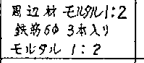 & 48 & $\mid \begin{array}{l}42.8 \\
(8-4)\end{array}$ & 2.8 & 204 & 1.8 & $\begin{array}{c}181 \\
(230)\end{array}$ & \begin{tabular}{|c|}
147 \\
$6177)$
\end{tabular} & $\begin{array}{r}5 \times 25 \\
6 A-5)\end{array}$ & $\mid \begin{array}{l}\left(30^{\circ}\right) \\
(c-3)\end{array}$ & $(0.54)$ & $\left|\begin{array}{l}(33) \\
(c-33\end{array}\right|$ & 3.5 & 1.25 \\
\hline 14 & 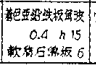 & 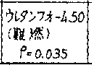 & 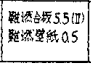 & 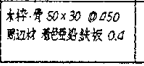 & 78 & $\mid \begin{array}{c}19 \\
(A-5)\end{array}$ & 3.9 & $\left|\begin{array}{r}230 \\
(B-4)\end{array}\right|$ & 2 & $\left|\begin{array}{c}193 \\
(290)\end{array}\right|$ & $\begin{array}{r}152 \\
11883\end{array}$ & $\left|\begin{array}{l}20 \times 250 \\
(A-6)\end{array}\right| c$ & $\left|\begin{array}{c}8^{\prime} \\
(E+1)\end{array}\right|$ & $\left|\begin{array}{c}(6.47) \\
(A-5)\end{array}\right|$ & {$\left[\begin{array}{c}(28) \\
(c-3)\end{array}\right]$} & 4 & 1.03 \\
\hline
\end{tabular}

は難然 (6.5 分) 以上とした。

（2）パネルの総合性能を示すと表一1の通りである。 a. 安全スパンについて(表面から加圧した場合)…… 屋根用として $230 \mathrm{~kg} / \mathrm{m}^{2}, \delta=l / 100$ でスパン $3 \mathrm{~m}$ 内外に 適用できるパネルは No. 1， スパン $2.5 \mathrm{~m}$ 内外のもの は No. 2, 7, 8 壁用として $125 \mathrm{~kg} / \mathrm{m}^{2} ， \delta=l / 200$ で久 パン $2.5 \mathrm{~m}$ に邂用できるものは No. $1,2 \mathrm{~m}$ 以上には No. 2, 5, 6, 7, 8, 10 が合格する。

b. 防火性能について……外面材の改良により，防火 性能の向上したパネルが多くなった。30 分に合格する パネルは No. 1，8，10，12，13 の 5 パネル20 分に 合格するものは No. 9 の 1 パネル 10 分に合格するも のは No. 2, 3, 6, 7, 11 の 5 パネル 6 分 30 秒 (内装 難然）に合格するものは No. 4，5，14の3 パネルとい う良好な結果が出た。

c. 経済性からみて, 単位価格 $\left(1000 \mathrm{~m} / \mathrm{m}^{2}\right)$ 当りの 平均号数は, No. 7 パネル以外はすべて 1 1.6 の性能 を示した。

(3) $36,37,38$ 年度の軽量パネルの平均性能を比較 してみると，38 年度パネルの性能が最 む问上したものは強度性能であり, 36 年 度に比して 2.8 倍, 防火性では $10 \%$ 上 昇し，その反面洒格は $15 \%$ の低下をみ た，この結果同一強度を得るための価格 は $69 \%$ 低下し，同一防火性能では $24 \%$ 低下した。すなわち単位価格からみた性 能は最大荷重で 3.24 倍防火性では 1.3 倍と著しく改良された。

\footnotetext{
* 東京大学教授 $\left(\right.$ 生研) - 工博 $*^{2}$ 同助手 $*^{3}$ 同研究嘱託 $*^{4}$ 、同研究補助員
} 